\title{
In Situ Localization of PCR-amplified Human and Viral CDNAs
}

\author{
Gerard J. Nuovo, ${ }^{1,2}$ Gina A. Gorgone, ${ }^{3}$ Phyllis MacConnell ${ }^{1}$ Michele Margiotta, ${ }^{1}$ and \\ Peter D. Gorevic ${ }^{3}$
}

Departments of ${ }^{1}$ Pathology, ${ }^{2}$ Obstetrics and Gynecology, and ${ }^{3}$ Medicine, SUNY at Stony Brook, Stony Brook, New York 11794

\begin{abstract}
We describe a technique, called reverse transcriptase (RT) in situ PCR, whereby RNA may be nonisotopically detected in fixed cells when amplified by PCR after CDNA synthesis by RT. RT in situ PCR using primers specific for the measles virus generated an intense signal in most measles-infected HeLa cells, as compared to the weak signal generated in few cells using standard in situ hybridization analysis. The viral RNA that localized to the nucleus spared the nucleoli, was most evident when the RT step used the primer complementary to the negative genomic strand, and was demonstrated in all multinucleated cells and the majority of uninucleate cells. A hybridization signal was evident with standard RNA in situ hybridization using the human megakaryocyte cell line Dami and a probe for glycoprotein IIB (CIIB) mRNA but not a probe for amyloid precursor protein (APP) or gelsolin (GEL) mRNA. After RT in situ PCR, signals were evident for each target localizing to the nucleolus for APP and to perinucleolar and cytoplasmic locations for GEL and GIIB. The latter findings suggest that mRNAs may follow different geographic pathways as they progress from premessage to transcriptionally active message.
\end{abstract}

$\mathbf{T}$ he study of the cellular and tissue distribution patterns of DNA and RNA has been greatly facilitated by in situ hybridization. However, one limitation of in situ hybridization is its relatively high detection threshold, which is about 20 copies per cell. ${ }^{(1)}$ Recent work on the processing of RNAs has focused on the nuclear matrix, which appears to provide a specific and obligatory pathway for this processing from transcription to splicing up to and including release of translationally active message into the cytoplasm. ${ }^{(2-6)}$ One observation supporting this hypothesis is the intimate association of the specific small nuclear (sn) RNAs and their associated proteins in spliceosomes, which are essential for splicing of pre-mRNA, with the nuclear matrix. ${ }^{(7,8)}$

The inability to detect low copy numbers of RNA has hindered the study of the dynamics and subcellular organization of mRNA transcription, processing, and transport. Wang et al. ${ }^{(9)}$ injected labeled $\beta$-globin pre-mRNA into nuclei and observed discrete subnuclear compartmentalization of the signal. Others have noted a dramatic compartmentalization of pre-mRNAs in the nucleus. ${ }^{(10)}$

Detection of in situ PCR-amplified DNA from a single DNA molecule per cell has been described, ${ }^{(1,11)}$ and the 100 -fold amplification is readily detected by in situ hybridization analysis. The hot start modification to the PCR in situ technique was used to improve sensitivity by increasing the amount of specific target synthesis and reducing the nonspecific amplification that may follow extension of primers annealed to nontarget sequences (mispriming) and extension of primers after they anneal over parts of their sequence to form primer oligomers. This enhanced speci- ficity allows the incorporation of a labeled nucleotide into the amplified product with the assurance that the resultant signal reflects target-specific amplification. (11)

In this manuscript, we describe a technique for in situ detection of PCRamplified cDNA and thus extend the hot start in situ PCR methodology to RNA targets. The technique is used to study the cytological correlates of measles infection in HeLa cells and the cellular compartmentalization of several human mRNAs.

\section{MATERIALS AND METHODS}

\section{Cell preparation}

The human megakaryocyte cell line Dami was grown as previously reported. ${ }^{(12)}$ HeLa cells (ATCC \# CCL2) were infected with the Edmonston strain of the measles virus (ATCC \# VR-24) and cultured for 1-3 days until the multinucleation characteristic of viral infection became evident. After overnight fixation in $10 \%$ buffered formalin, about 1000 cells were placed on silane-coated glass slides using a cytospin centrifuge at 90 rpm for 2 min.

\section{RNA In Situ Hybridization}

Standard in situ hybridization was done according to a previously published protocol. ${ }^{(13)}$ Briefly, the hybridization cocktail contained $50 \%$ formamide, $150 \mathrm{~mm}$ $\mathrm{NaCl}, 10 \%$ dextran sulfate, and the cDNA or olioprobe (see below) at $500 \mathrm{ng} / \mathrm{ml}$. Each probe, except for the measles oligoprobe that was used only for the RT in situ PCR hybridization assay, was labeled with digoxigenin dUTP (kindly supplied by Boehringer Mannheim, Indianapolis, 
TABLE 1 Sequences of Primers Used in Analysis of RNAs

\begin{tabular}{lllcc}
\hline Target & & \multicolumn{1}{c}{ Sequence } & Nucleotides & Reference \\
\hline Measles & $\left(5^{\prime}\right)$ & CAAACACATTATTATAGTAC & $201-220$ & 15 \\
& $\left(3^{\prime}\right)$ & TTTTCTCTCCAATCTAAAT & $830-811$ & 23 \\
APP & $\left(5^{\prime}\right)$ & CACCACAGAGTCTGTGGAAG & $958-977$ & \\
& $\left(3^{\prime}\right)$ & AGGTGTCTCGAGATACTTGT & $1213-1194$ & 24,25 \\
GIIb & $\left(5^{\prime}\right)$ & GAGCTGCAGATGGACGCAGCCAAC & $1988-2011$ & \\
& $\left(3^{\prime}\right)$ & CAGGAAGGCCAGCACCGTGACCAT & $2821-2797$ & 26 \\
GEL & $\left(5^{\prime}\right)$ & TGGTGGTGCAGAGACTCTTCC & $565-585$ & \\
& $\left(3^{\prime}\right)$ & GTTGCCCAGGTCCAGGAT & $680-663$ & \\
\hline
\end{tabular}

Indiana) by nick-translation according to the manufacturer's recommendations. The measles oligoprobe was generated from an internal 20-mer fragment $^{(14)}$ end-labeled with digoxigenin using terminal transferase (Genius 5 kit, kindly supplied by Boehringer Mannheim). Because in our experience oligoprobes can give diminished signals, a probe generated by nick-translation from the 115- to 809-bp fragment (Table 1) generated by the four sets of primers used in this study with the corresponding cDNA clone as target was used in standard RNA-cDNA in situ hybridization. The probe and target RNA were heated at $65^{\circ} \mathrm{C}$ for $15 \mathrm{~min}$, followed by a 2-hr hybridization and detection of the labeled probe/target complex as previously reported. ${ }^{(1,11)}$ The alkaline phosphatase-based colorimetric detection method results in a purple-blue precipitate at the site of hybridization. The counterstain, nuclear fast red, stains negative nuclei pale pink and does not stain cytoplasm.

\section{RT In Situ PCR}

In preparation for cDNA synthesis, the cells were first digested with trypsin (2 $\mathrm{mg} / \mathrm{ml}, 37^{\circ} \mathrm{C}$; Life Technologies, Gaithersburg, Maryland) for $12 \mathrm{~min}$ and then treated overnight in a RNase-free DNase solution made according to the manufacturer's recommendations ( $1 \mathrm{unit} / \mu \mathrm{l}$, $37^{\circ} \mathrm{C}$, Stratagene, LaJolla, California). The cells were incubated directly on the glass slide at $42^{\circ} \mathrm{C}$ for $30 \mathrm{~min}$ with a solution that contained the downstream primer $(1 \mu \mathrm{M})$ and reverse transcriptase made according to the manufacturer's protocol (RT-PCR kit, kindly supplied by Perkin-Elmer Corporation, Norwalk, Connecticut). To prevent evaporation, the solution was covered with a plastic coverslip, which was anchored with a drop of nail polish. The glass slide was placed in an aluminum "boat" directly on the block of the thermocycler (Perkin-Elmer Cetus Instruments). After the RT step, the slides were placed in xylene for 2 min to remove the mineral oil and then in $100 \%$ ethanol for $2 \mathrm{~min}$ to remove the xylene. Briefly, the hot start in situ protocol ${ }^{(11)}$ was as follows: $2 \mu$ l of the DNA amplifying solvent containing 2.0 units of Taq DNA polymerase (AmpliTaq DNA polymerase, Perkin-Elmer) was withheld from the initial amplifying solution, which contained $4.5 \mathrm{mM} \mathrm{MgCl}_{2}$, $200 \mu \mathrm{M}$ dNTPs, $10 \mu \mathrm{M}$ digoxigenin dUTP, and $1 \mu \mathrm{M}$ of the primers. The heating

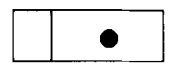
and anchor with nail polish

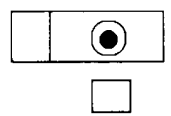
overlay with mineral oil

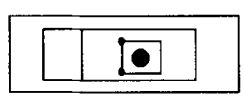

block was brought to $82^{\circ} \mathrm{C}$, the coverslip lifted, and the enzyme added. The coverslip was then overlaid with about $1 \mathrm{ml}$ of mineral oil preheated to $82^{\circ} \mathrm{C}$. After an initial denaturing step of $94^{\circ} \mathrm{C}$ for $3 \mathrm{~min}$, 25 cycles were accomplished using the following protocol: annealing/extension at $55^{\circ} \mathrm{C}$ for $2 \mathrm{~min}$ and denaturation at $94^{\circ} \mathrm{C}$ for $1 \mathrm{~min}$. After successive 3 -min washes in xylene and $100 \%$ ethanol, the labeled DNA was detected using alkaline phosphatase-conjugated anti-digoxigenin antibody (Boehringer Mannheim) and NBT/BCIP as described previously. ${ }^{(11)}$ The technique is graphically represented in Figure 1.

For the measles target, the primers used correspond to the nucleocapsid region of the virus. ${ }^{(14)}$ The sequences of these primers and those used for the analysis of APP, GIIb, and GEL in the human cells are listed in Table 1 . To demonstrate the success of the DNase pretreatment, in situ PCR was performed with the HeLa cells (which contain about 20 copies of HPV 18/cell) ${ }^{(15)}$ and Dami cells using primers for human papillomavirus type 18 (HPV-18) and the

1. Paraffin-embedded tissue or cytospin on silane-coated glass slide; digest with protease solution, then RNase-free DNase

2. Add RT solution with downstream primer, plastic coverslip

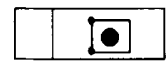

3. Place in aluminum boat, then on Thermal Cycler at $42 \mathrm{C}$ for $30 \mathrm{~min}$,

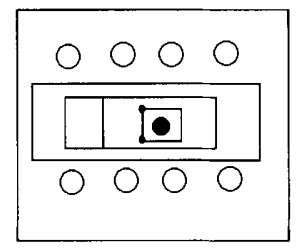

4. Remove solution with xylene and $100 \%$ ethanol washes, add PCR-amplifying solution minus the Taq polymerase

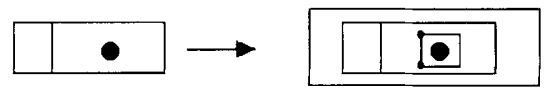

5. Place on Thermal Cycler, add Taq at $60 \mathrm{C}$ by lifting coverslip, overlay with preheated mineral oil, denature, cycle

FICURE 1 Graphic representation of the RT in situ PCR technique. 
gene $b c l$-2 (kindly supplied by Dr. Ernest Kawasaki, Roche Molecular Diagnostics) present in each cell, respectively.

\section{RESULTS}

The cytological appearance of the HeLa cells infected by the measles virus is characteristic and is shown in Figure 2a. The cells are multinucleated and each nucleus contains one to several inclusions. Of the uninucleate cells, $112 / 200$ $(56 \%)$ also show intranuclear inclusions. Standard cDNA-RNA in situ hybridization was performed and a signal was evident in the nucleus and cytoplasm of only a few of the multinucleated cells and none of the uninucleate cells (Fig. 2b).

These results were compared to those obtained with RT in situ PCR. The cells were first treated with RNase-free DNase to reduce the chance of mispriming, although this process is greatly reduced by the hot start modification of PCR. ${ }^{(11)}$ HeLa cells contain about 20 copies of in- tegrated (HPV-18) DNA per cell. DNase pretreatment rendered native DNA nonamplifiable, as evidenced by the loss of signal after in situ PCR using primers for HPV-18 ${ }^{(16)}$ (data not shown, although see Fig. 4b,c for comparable results). After RT in situ PCR for measles cDNA using both primers for the RT step, all cells with multiple nuclei had an intense signal (Fig. 2c). The staining was evident in both the cytoplasm and nucleus (Fig. $2 \mathrm{~d})$. Note that the RT-PCR-derived nuclear signal typically spared one focus per nucleus. This nonstaining nuclear area corresponded to the inclusions noted by light and electron microscopy (Fig. 2c). Of the uninucleate cells, 130/ $200(65 \%)$ had a detectable signal. To demonstrate the specificity of direct incorporation, measles-infected HeLa cells were mixed with peripheral leukocytes from an individual with no evidence of measles infection. Only the measles-infected HeLa cells had a detectable signal (Fig. 2d). The signal was eliminated if the RT step was preceded by a 2 -hr digestion in RNase $\left(1 \mathrm{mg} / \mathrm{ml}\right.$ at $37^{\circ} \mathrm{C}$ for $\left.2 \mathrm{hr}\right)$. RTPCR in situ hybridization was performed in which unlabeled nucleotide was incorporated by RT-PCR followed by standard in situ hybridization using an internal oligoprobe. A hybridization signal was evident under these conditions (Fig. 2e).

Measles is a minus-strand virus; this genomic strand has been identified in the nucleus, compared to the plus message strand, which localizes to the cytoplasm of infected cells. ${ }^{(19)}$ To determine the relative contribution to the signal of the sense and antisense primers, the experiments were repeated using just one of the primers for RT. The pattern after RT in situ PCR for measles cDNA in which the primer complementary to the minus (antisense) strand was used for the RT step gave nuclear results equivalent to those described above: All multinucleate cells and many uninucleate cells had detectable signal. When RT used the primer complementary to the plus (sense) strand, the results were very
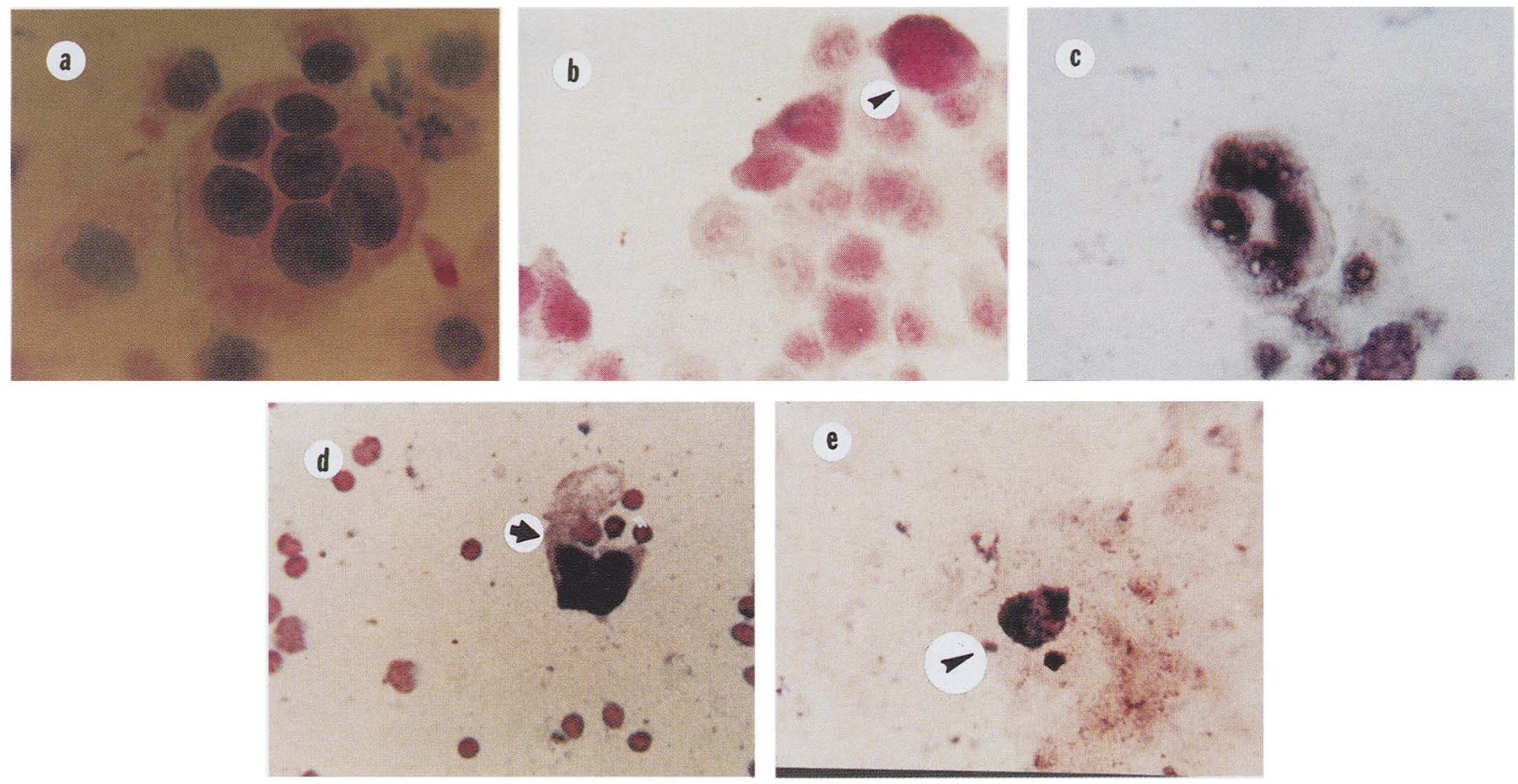

FICURE 2 Cytological and molecular analysis of measles-infected HeLa cells. The multinucleation and nuclear inclusions characteristic of measlesinfected cells are evident on routine H\&E staining $(a)$. A few nuclei from the multinucleated cells demonstrated a hybridization signal with standard in situ hybridization $(b)$. All such nuclei were positive and the signal was intense after in situ detection of amplified cDNA using measles-specific primers and direct incorporation of digoxigenin-labeled nucleotide; note the sparing of the area corresponding to the inclusions (c). Only the measles-infected HeLa cells were positive using direct incorporation when these cells were mixed with peripheral blood leukocytes; note the cytoplasmic signal (arrow, $d$ ). A strong hybridization signal was evident using standard in situ hybridization after amplification of the cDNA with incorporation of unlabeled nucleotides $(e)$. The counterstain in $b-e$ is nuclear fast red and the blue precipitate signal is the result of the action of alkaline phosphatase on NBT/BCIP. 
different; only $1 \%$ of the cells had a detectable nuclear signal (data not shown).

Electron microscopy of the infected HeLa cells demonstrated scattered nucleocapsid in the cytoplasm and nucleus in the form of tubulo-reticular bodies (Fig. 3 ). These inclusions were noted in about $10 \%$ of cells. A similar percentage of cells had detectable nucleocapsid antigen, as noted with an immunohistochemical assay using a monoclonal antibody (Chemicon MAB8920, Temecula, California) and a previously published protocol. $^{(11)}$ Note the prominent nucleoli evident on ultrastructural examination that correspond to the nuclear inclusions and to the areas that are negative by RT in situ PCR.

To determine if human mRNA could function as the target molecule, the megakaryocyte line Dami was analyzed for three different mRNA moleculesGEL, GIIB, and APP. GEL is an actinbinding protein that co-localizes with the cytoskeleton during platelet activation. ${ }^{(17)}$ GIIB is a specific membrane marker of cells of megakaryocyte cell lineage and should be the most abundant message in Dami cells. ${ }^{(12)}$ The message for APP is encoded by many cell types, including platelets and megakaryocytes. ${ }^{(18)}$ The morphological appearance of the Dami cells is seen in Fig. 4a. Note that one to four nucleoli are present per nucleus. Because the cellular DNA contains DNA sequences homologous to the primers used for RT and subsequent PCR, the RT in situ PCR was preceded by
RNase-free DNase treatment. The DNase eliminated the ability of primers for the proto-oncogene $b c l-2$, a DNA sequence present in each of the human cells, to produce a signal (Fig. 4, b versus c). Standard in situ hybridization was then performed under conditions that should allow only RNA-cDNA complexing using digoxigenin-labeled probes for APP, GEL, and GIIB. As seen in Figure 4, a hybridization signal was evident under these conditions only for GIIB and localized to both the nucleus and the cytoplasm. A signal was evident after RT in situ PCR for each of the three RNAs and localized to several discrete nuclear foci for APP (Fig. 4h). A complementary nuclear localization was evident for GEL, which also yielded a weak cytoplasmic
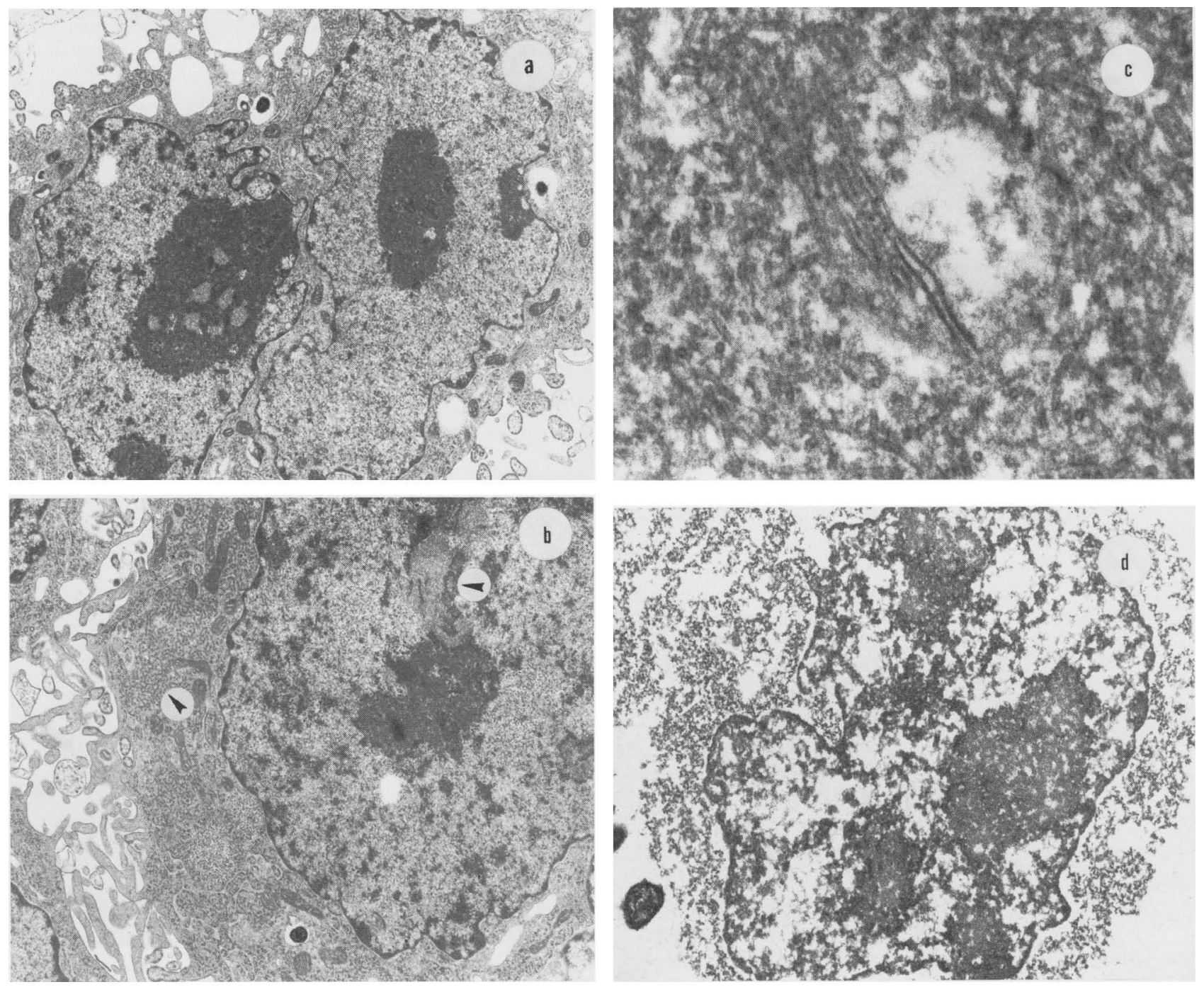

FIGURE 3 Electron microscopic analysis of measles-infected HeLa cells and Dami cells. The prominent nucleoli corresponding to the intranuclear inclusions of measles-infected HeLa cells is evident in $a(6,000 \times)$. Tubulo-reticular inclusions corresponding to the naked nucleocapsid of the virus were occasionally seen in the nucleus and cytoplasm (arrows; $b, 10,000 \times$ ) and at higher magnification $(c, 90,000 \times$ ). The multiple nucleoli characteristic of Dami cells is seen in $d(6,000 \times)$. 


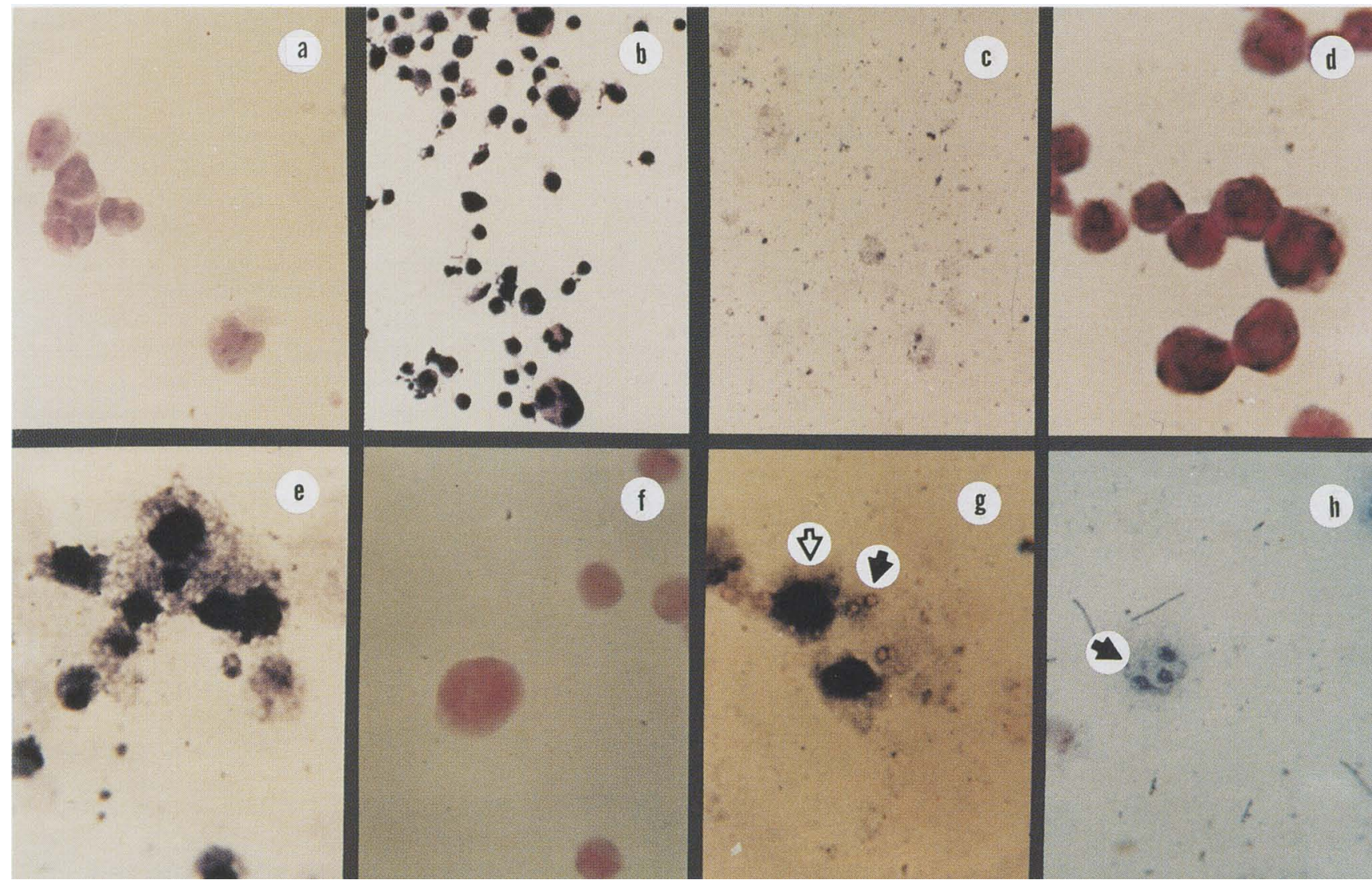

FIGURE 4 Cytological and molecular analysis of Dami cells. The multiple small nucleoli and moderate amount of cytoplasm of Dami cells as seen with routine H\&E staining is shown in $a$. The signal derived from the $b c l-2$ DNA present in each cell was evident using in situ PCR $(b)$ and was eradicated with prior treatment of RNase-free DNase (c). A weak nuclear and cytoplasmic signal was noted with standard RNA in situ hybridization for GIIB $(d)$. These signals were much more intense after RT in situ PCR with DNase pretreatment ( $e$, reticular staining pattern is in cytoplasm). No signal was seen with standard RNA in situ hybridization for GEL $(f)$ and APP (not shown). Strong signals were evident for each after RT in situ PCR in a perinucleolar (closed arrow) and cytoplasmic distribution (open arrow) for GEL $(g$ ) and in a nucleolar (arrow) but not cytoplasmic distribution for $\operatorname{APP}(h)$.

signal (Fig. 4g, arrow). A similar, though much more intense, nuclear and cytoplasmic signal was seen with GIIB (Fig. $4 \mathrm{e})$; the perinucleolar distribution was evident in rare cells owing to the overall strong intensity of the nuclear signal. The signals for each of the mRNA were not evident if the RT step of the RT in situ PCR technique was omitted. Electron microscopy showed that the nuclear foci evident with APP and spared for GEL and GIIB corresponded to the nucleoli (Fig. 3d).

A relative comparison of the detection thresholds for in situ detection of nucleic acids with and without PCR amplification based on this and prior work is presented in Table 2 .

\section{DISCUSSION}

This study extends the technique of in situ detection of PCR-amplified DNA to
RNA. We previously reported that PCR in situ hybridization can readily detect one copy of a target sequence per cell. ${ }^{(1,11)}$ Thus, RT in situ PCR should allow for the direct visualization in intact cells of the corresponding cDNA synthesized from the target RNA molecule even when present as a single copy. However, this statement must be tempered by the realization that we thus far have not shown that one copy of RNA is invariably made into cDNA in the RT step of this technique.

In both the measles-infected HeLa cells and Dami cells, the RNA-generated signal was localized. For the measles-infected cells, the reason for the localization was evident on routine light microscopy. The nuclear areas without a detectable signal corresponded to the inclusions, shown on electron microscopy to be the prominent nucleoli characteristic of the infected cell. Viral RNA was detected in the uninucleate cells in a ratio equivalent to the inclusions evident on routine microscopic examination. This shows that the inclusions are a reliable marker of measles infection in cells that have not acquired multiple nuclei.

Measles is a minus-stranded RNA virus and the genomic RNA can be present in the nucleus as part of a RNA-protein complex, whereas the plus message strands are cytoplasmic in location ${ }^{(19)}$ (W. Bellini, personal communication). The detection of a nuclear signal in most cells in which the primer complementary to the antisense strand is used in RT in situ PCR and the marked reduction in positive nuclei when using the primer complementary to the sense strand for RT in situ PCR is consistent with these observations. Cytoplasmic signal that probably represents viral message was evident when the primer complementary to the sense strand was included in 
TABLE 2 Relative Sensitivities of In Situ Hybridization with and without PCR Amplification

\begin{tabular}{llll}
\hline & & \multicolumn{2}{c}{ In situ signal } \\
\cline { 4 - 4 } Cell line (reference) & Target/copy per cell & \multicolumn{1}{c}{ without PCR } & with PCR \\
\hline DNA & & & \\
SiHa (11) & HPV $16 / 1$ copy & negative & positive \\
PBMs & Bcl-2/2 copies & negative & positive \\
HeLa (1) & HPV-18/20 copies & weakly positive & strongly positive \\
Caski (1) & HPV-16/600 copies & strongly positive & strongly positive \\
RNA & & & \\
HeLa & measles/1-30 copies & weakly positive & strongly positive \\
Dami & GIIB/100 copies & moderately positive & strongly positive \\
Dami & GEL/1-20 copies & negative & positive \\
Dami & APP/1-20 copies & negative & positive \\
Liver biopsy & hepatitis C/1-30 copies & weakly positive & strongly positive \\
\hline
\end{tabular}

a(PBMs) Peripheral blood mononuclear cells.

${ }^{b}$ G.J. Nuovo, in prep.

RT but tended to be less conspicuous than the nuclear signal. This may represent relative minimal production of the message corresponding to the nucleocapsid region, as suggested by the electron microscopy, and immunohistochemical findings. Another possible explanation is that amplified product in the nucleus tends to diffuse less than amplified product in the cytoplasm, making the latter more difficult to detect.

The signal generated with the human RNAs was most likely derived from transcripts after extensive splicing because the cells were pretreated with RNase-free DNase and due to the large size of the transcripts prior to intron splicing (up to $20 \mathrm{~kb}$ ). Discrete cellular localization was dramatic with the three human mRNAs studied in the human megakaryocyte line. Interestingly, the signal localized to foci corresponding to the nucleoli for APP but not to the cytoplasm. Both nuclear and cytoplasmic signals were evident with GEL and GIIB, but the distribution of the nuclear signal was perinucleolar. One interpretation of these data is that the subnuclear localization reflects different geographic routes taken by these RNAs as they proceed from pre-mRNA to active message. Discrete localization has been demonstrated by others for several pre-mRNAs. ${ }^{(9-11)}$ In this regard, it is of interest that U3, one of the snRNAs essential in the splicing apparatus, localizes to the nucleolus whereas the other snRNAs studied have a perinucleolar distribution. ${ }^{(7)}$ Whether our results indicate differential localization of the RNAs along the nuclear matrix will require further study.
No hybridization signal was evident with standard RNA-cDNA in situ hybridization for GEL or APP. This suggests that the copy number of these messages per cell is less than $20 .^{(1,13)}$ A signal was evident for each of these mRNAs after PCR amplification of the corresponding cDNA. A cytoplasmic signal was evident with GEL and GIIB but not APP. One possible explanation is that the cytoplasmic mRNA for the latter is degraded. This seems unlikely given the presence of the nucleolar signal and the cytoplasmic signals for the other two RNAs. It is feasible that amplified cDNAs may be more difficult to detect in the cytoplasm relative to the nucleus, given the larger volume of the former and perhaps, as discussed above for the measles virus, a relative greater diffusibility in the cytoplasm. Another explanation to consider is that the APP pre-mRNA may have been synthesized and processed in the cell but that under the conditions of this study the end step of transport to the cytoplasm of translationally active message has not occurred. Xing and Lawrence ${ }^{(4)}$ noted a nuclear signal but no cytoplasmic signal for some pre-mRNAs and speculated that the nuclear matrix may play a role in the release of the active message into the cytoplasm. We are in the process of analyzing this issue using conditions known to induce the synthesis of active message in various cell lines. Preliminary data with proteins inducible with phorbol myristate acetate have shown that a signal is evident in few cells before stimulation of mRNA synthesis but that a cytoplasmic signal is evident in most cells after stimulation using the RT in situ PCR methodology (D.
French and G.J. Nuovo, unpublished observations).

Target-specific amplification during PCR may be inhibited by unwanted side reactions that include mispriming and primer oligomerization. Hot start PCR, a method whereby at least one reagent is withheld until the reaction temperature has reached at least $50^{\circ} \mathrm{C}$ at the initiation of cycling, greatly reduces the nonspecific pathways and increases the yield of specific product. ${ }^{(12,20)}$ Hot start in situ PCR is sufficiently specific to permit direct incorporation of labeled nucleotide only into target sequences. ${ }^{(12)}$ The experiments reported in this manuscript, which included DNase pretreatment, the use of mixed cell populations, and the use of confirmatory labeled probes, also indicate the specificity of hot start-mediated direct incorporation of labeled nucleotide. The technique described in this study used nonisotopic probes and nucleotides, which are easier to work with and give more rapid results than radioactive labeled systems. Furthermore, with improvements in detection systems for nonisotopic reporter molecules, their sensitivity is now equivalent to radioactive systems. ${ }^{(21)}$ RT in situ PCR can be completed within $24 \mathrm{hr}$ and its use should facilitate the study of the synthesis and processing of low-copy-number mRNAs and RNA viruses in cells and tissue sections. ${ }^{(22)}$

\section{ACKNOWLEDGMENTS}

The authors greatly appreciate the technical and material assistance of Drs. John Atwood, Will Bloch, Deborah French, Dennis Groff, Larry Haff, Brian Holaway, John Sninsky, and Eric Spitzer. We also appreciate the editorial assistance of Drs. Will Bloch, James Quigley, and Gary Zieve. Ms. Angella Forde, Frances Gallery, and Kim Rhatigan provided expert technical assistance. We are especially indebted to Dr. Selaki for providing the measles-infected HeLa cells and Mr. S.B. Lewis for his financial support. This work was supported by a grant from the Lewis Foundation to G.J.N.

\section{REFERENCES}

1. Nuovo, G.J., P. MacConnell, A. Forde, and P. Delvenne. 1991. Detection of human papillomavirus DNA in formalin fixed tissues by in situ hybridization after amplification by PCR. Am. J. Pathol. 139: 847854 . 
2. Fey, E.G., G. Krochmalnic, and S. Penman. 1986. The nonchromatin substructures of the nucleus: the ribonucleoprotein (RNP)-containing and RNP-depleted matrices analyzed by sequential fractionation and resinless section electronmicroscopy. J. Cell. Biol. 102: 1654-1665.

3. Lawrence, J.B., R.H. Singer, and L.M. Marselle. 1989. Highly localized tracks of specific transcripts within interphase nuclei visualized by in situ hybridization. Cell 57: 493-502.

4. Xing, Y. and J.B. Lawrence. 1991. Preservation of specific RNA distribution within the chromatin-depleted nuclear substructure demonstrated by in situ hybridization coupled with biochemical fractionation. J. Cell. Biol. 112: 1055-1063.

5. Verheijen, R., W. Van Verrooji, and F. Ramaekers. 1989. The nuclear matrix: Structure and composition. J. Cell. Sci. 90: 1136.

6. Mirkovitch, J., M.E. Mirault, and U.K. Laemmli. 1984. Organization of the higher-order chromatic loop: Specific DNA attachment sites on nuclear scaffold. Cell 39: 223-232.

7. Carmo-Fonesca, M., D. Tollervey, R. Pepperkok, S.M.L. Barabino, A. Merdes, C. Brunner, P.D. Zamore, M.R. Green, E. Hurt, and A.I. Lamond. 1991. Mammalian nuclei contain foci which are highly enriched in components of the pre-mRNA splicing machinery. EMBO J. 10: 195206.

8. Zamore, P.D. and M.R. Green. 1991. Biochemical characterization of U2 snRNP auxiliary factor: an essential pre-mRNA splicing factor with a novel intranuclear distribution. EMBO J. 10: 207-214.

9. Wang, J., L.G. Cao, Y.L. Wang, and T. Pederson. 1991. Localization of premessenger RNA at discrete nuclear sites. Proc. Natl. Acad. Sci. 88: 7391-7395.

10. Lawrence, J.B., L.M. Marselle, K.S. Byron, C.V. Johnson, J.L. Sullivan, and R.H. Singer. 1990. Subcellular localization of low-abundance human immunodeficiency virus nucleic acid sequences visualized by fluorescence in situ hybridization. Proc. Natl. Acad. Sci. 87: 5420-5424.

11. Nuovo, G.J., F. Gallery, P. MacConnell, J. Becker, and W. Bloch. 1991. An improved technique for the in situ detection of DNA after polymerase chain reaction amplification. Am. J. Pathol. 139: 1239-1244.

12. Greenberg, J.M., D.J. Rosenthal, T.A. Greeley, R. Tantravah, and R.J. Hardin. 1988. Characterization of a new megakaryocyte cell line: The Dami cell. Blood 72: 1968-1974.

13. Crum, C.P., G. Nuovo, D. Friedman, and S.J. Silverstein. 1988. Accumulation of RNA homologous to human papillomavirus type 16 open reading frames in genital precancers. J. Virol. 62: 84-90.

14. Rozenblatt, S., O. Eizenberg, R. Ben-Levy,
V. Lavie, and W.J. Bellini. 1985. Sequence homology within the morbilliviruses. $J$. Virol. 53: 684-690.

15. Yei, C., I. Kristan-Hewlett, C.C. Baker, and P.M. Howley. 1985. Presence and expression of human papillomavirus references in human cervical carcinoma cell lines. Am. J. Pathol. 119: 361-367.

16. Nuovo, G.J., M.M. Darfler, C.C. Impraim, and S.E. Bromley. 1991. Occurrence of multiple types of human papillomavirus in genital tract lesions: Analysis by in situ hybridization and the polymerase chain reaction. Am. J. Pathol. 58: 518-523.

17. Hartwig, K., K.A. Chambers, and T.P. Stossel. 1989. Localization of gelsolin with actin filaments in cell membranes of macrophages and platelets. I. Cell. Biol. 108: 467-479.

18. Gardella, J.E., G.A. Gorgone, P.J. Newman, B. Frangione, and P.D. Gorevic. 1992. Characterization of alzheimer amyloid precursor protein transcripts in platelets and megakaryocytes. Neurosci. Lett. (in press).

19. Norrby, E. and M.V. Oxman. 1990. Measles. In Fields virology (ed. B.N. Fields and D.M. Knipe), vol. 1, pp. 1013-1036. Raven Press, New York.

20. Erlich, H.A., D. Gelfand, and J.J. Sninsky. 1991. Recent advances in the polymerase chain reaction. Science 252: 1643-1650.

21. Nuovo, G.J. 1989. A comparison of different in situ hybridization methodologies (biotin based and ${ }^{35} \mathrm{~S}$ based) for the detection of human papillomavirus DNA. Lab. Invest. 61: 471-476.

22. Nuovo, G.J. 1992. PCR in situ hybridization: Protocols and applications. Raven Press, New York.

23. Ponte, P., P. Gonzalez-Dewhitt, J. Schilling, J. Miller, D. Hsu, B. Greenberg, K. Davis, W. Wallace, I. Lieberburg, and F. Fuller. 1988. A new A4 amyloid mRNA contains a domain homologous to serine proteinase inhibitors. Nature 331: 525527.

24. Pontz, M., R. Eisman, R. Heidenreich, S.M. Silver, G. Vilaire, S. Surrey, E. Schwartz, and J. Bennet. 1987. Structure of the platelet membrane glycoprotein IIB. J. Biol. Chem. 262: 8476-8482.

25. Lyman, S., R.H. Aster, G.P. Visentin, and P.J. Newman. 1990. Polymorphism of human platelet membrane glycoprotein IIB associated with the Baka/Bakb alloantigen system. Blood 75: 2343-2348.

26. Kwiatkowski, D.J., T.P. Stossel, S.H. Orkin, J.E. Mole, H.R. Colten, and H.L. Yin. 1986. Plasma and cytoplasmic gelsolins are encoded by a single gene and contain a duplicated actin-binding domain. $\mathrm{Na}$ ture 323: 455-458.

Received June 19, 1992; accepted in revised form August 19, 1992. 


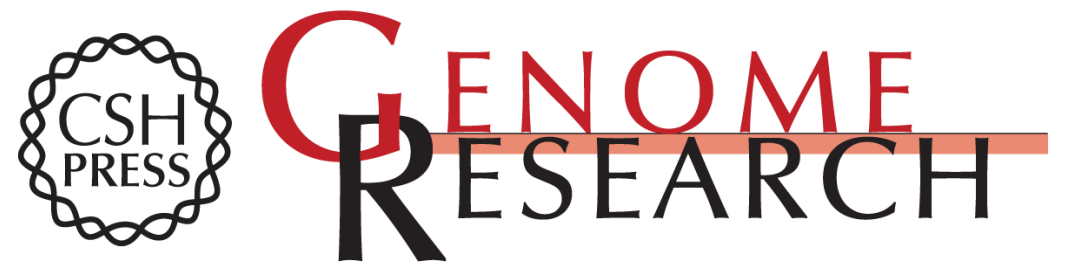

\section{In situ localization of PCR-amplified human and viral cDNAs.}

G J Nuovo, G A Gorgone, P MacConnell, et al.

Genome Res. 1992 2: 117-123

Access the most recent version at doi:10.1101/gr.2.2.117

References This article cites 23 articles, 11 of which can be accessed free at:

http://genome.cshlp.org/content/2/2/117.full.html\#ref-list-1

\section{License}

Email Alerting Receive free email alerts when new articles cite this article - sign up in the box at the Service top right corner of the article or click here.

\section{Affordable, Accurate Sequencing.}

To subscribe to Genome Research go to: https://genome.cshlp.org/subscriptions 